\title{
Study of feto-maternal outcome in previous cesarean section
}

\author{
Mahantappa A. Chiniwar* \\ Department of Obstetrics and Gynecology, Adichunchanagiri Institute of Medical Sciences Bellur, Bellur Tq
} Nagamangala, District Mandya, Karnataka, India

Received: 19 June 2018

Received: 10 July 2018

Accepted: 26 July 2018

\section{*Correspondence:}

Dr. Mahantappa A. Chiniwar,

E-mail: drmachiniwar@gmail.com

Copyright: (c) the author(s), publisher and licensee Medip Academy. This is an open-access article distributed under the terms of the Creative Commons Attribution Non-Commercial License, which permits unrestricted non-commercial use, distribution, and reproduction in any medium, provided the original work is properly cited.

\section{ABSTRACT}

Background: There is increase in number of primary cesarean sections, leading to more number of women facing the issue of mode of delivery in the current pregnancy. There are reports about success of vaginal birth after cesarean section as well as complications such as scar dehiscence, rupture of uterus, poor maternal and fetal outcome.

Methods: A prospective study was done for a period of $1 \mathrm{yr}$ and 9 months at Cheluvamba Hospital attached to Govt Medical College Mysore from October 99 to June 2000. Data regarding previous cesarean section was collected, clinical findings during the present pregnancy were noted.

Results: During the study period there were 942 women admitted with previous history of cesarean section. Elective repeat cesarean section was done for 530 cases and trial of labour after cesarean section was planned for 412 cases. Successful vaginal delivery was conducted in 311 cases. Repeat emergency cesarean section was done for 96 cases due to failed trial of labour. Maternal morbidity such as adhesions was seen in $11.25 \%$ and obliteration of $\mathrm{U} V$ fold in $7.92 \%$ of cases. Maternal mortality was seen in $0.15 \%$. Perinatal morbidity was seen in $3.32 \%$, perinatal mortality in $3.96 \%$

Conclusions: With increasing proportion of women with previous cesarean sections, it is essential to counsel these women during trial of vaginal delivery in well equipped hospitals. It is worth to reduce primary cesarean section to avoid complications in consequent pregnancies. Proper and timely decision for repeat cesarean sections will reduce fetal and maternal morbidity and mortality.

Keywords: Cesarean section, Neonatal Intensive Care Unit (NICU), PROM, Preterm labour, Trial of labour after cesarean (TOLAC), Vaginal birth after cesarean section (VBAC)

\section{INTRODUCTION}

Cesarean section (CS) is the commonest obstetric operative procedure. $\mathrm{CS}$ is usually performed when vaginal delivery put the baby or mother's life or health at risk, although recently it has also been performed upon maternal requests with non obstetric or medical indications. Medically justified cesarean section can effectively prevent maternal and perinatal mortality and morbidity. The International health care community has considered the ideal rate for C S to be $10-15 \%$ according to WHO guidelines published in 2015. The guidelines also state that cesarean sections can cause significant and sometimes permanent complications disability or death, particularly in poor hospital settings to conduct safe surgery and treat surgical complications. There is increasing trend of $\mathrm{CS}$ in developed and developing countries. The reasons are multifactorial like, increasing maternal age, associated medical risk factors, changing 
obstetric practices like, increase in the rate of induction of labour and continuous electronic fetal monitoring. ${ }^{1}$

Due to increased complications associated with vaginal birth after cesarean section (VBAC), prior CS forms a major indication for repeat $\mathrm{CS}$ and previous $\mathrm{CS}$ account for $8-40 \%$ of repeat cesarean sections. Both trial of labour and repeat CS carry risks, including maternal hemorrhage, infections, operative injury, hysterectomy and mortality. With increasing number of trial of labours after CS (TOLAC), there were reports of uterine scar dehiscence or rupture and associated maternal and fetal morbidity and mortality. A successful VBAC has fewer complications than an elective repeat cesarean, while a failed trial of labour has more complications than an elective repeat $\mathrm{CS} .^{1}$

Documentation that rate of uterine rupture is only marginally increased among women undergoing a trial of labour than among those underwent repeat CS $(0.4 \%$-vs $0.2 \% \mathrm{OR}=0.57)$, with a significant decrease in the need for blood transfusion $(\mathrm{OR}=0.57 \%)$ or hysterectomy $(\mathrm{OR}=0.39 \%)$ has lead authorities to encourage VBAC. A group of investigators concluded that among women with a previously scarred uterus, induction of labour is associated with an increased risk of rupture uterus compared with spontaneous labour $(2.3 \%$ vs $0.7 \%$ $\mathrm{p}=0.001)^{2}$

The present study was done to know the maternal and fetal outcome in patients with previous cesarean section and those required repeat $\mathrm{CS}$.

\section{METHODS}

This prospective study was done in Cheluvamba Hospital attached to Govt Medical College Mysore over a period of 1 yr 9 months (October 1999-June 2000). The study has been done on women admitted for safe confinement with previous cesarean section.

Inclusion criteria were: all women with previous one lower segment cesarean section, gestational age 37-40 wks.

Exclusion criteria were all women with previous h/o classical CS, more than one CS, hysterotomy, myomectomy.

Following details were noted down in a proforma. Detailed history was taken at the time of admission about previous CS, particulars regarding indications, post operative morbidity, wt of the baby. Detailed history during the present pregnancy, investigation reports and associated medical disorders were noted down. Women with previous one $\mathrm{C} \mathrm{S}$ done for non recurrent indication and a singleton cephalic presentation were counseled about the risks and benefits of Trial of labour after cesarean (TOLAC) versus elective repeat CS. Women who gave consent for TOL were admitted and monitored during labour for pulse, BP, fetal heart rate, uterine contractions, scar tenderness and progress of labour. Emergency CS was done for patients with non progress of labour and fetal distress. Intra and post operative findings were recorded. Perinatal details were noted.

Elective CS was decided for those women admitted with complications, completed $38 \mathrm{wks}$ and not willing for TOL. Intra and post operative findings were recorded. Maternal and perinatal findings were noted.

\section{RESULTS}

During the study period of $1 \mathrm{yr}$ and 9 months there were total 14164 admissions for safe confinement. Cesarean section was done for 2102 women, include primary and repeat cesarean section (rate of CS 14.84\%). There were 942 women with history of previous one CS. Elective CS was done for 530 cases and trial of labour was planned for 412 cases. Successful vaginal delivery was conducted for 311 cases and failure of trial among 101 cases and 96 women had emergency repeat CS. Incidence of repeat CS was $66.45 \%$. And 5 cases had scar dehiscence and closure of the rent ( 2 cases) and subtotal hysterectomy (3 cases) was done. Maternal mortality observed in one case who was admitted lately with history of leaking per vagina. Repeat CS was done, resulted in wound infection due to prolonged PROM and burst abdomen (0.42\%).

Table 1: Indications for CS in VBAC cases, elective CS, repeat CS in failed TOL.

\begin{tabular}{|llll|}
\hline Indications & $\begin{array}{l}\text { Elective } \\
\text { repeat } \\
\text { C S }\end{array}$ & VBAC & $\begin{array}{l}\text { C S in } \\
\text { failed } \\
\text { TOL }\end{array}$ \\
\hline Fetal distress & $16.41 \%$ & $18.64 \%$ & $52.08 \%$ \\
\hline Breech & $7.16 \%$ & $10.28 \%$ & - \\
\hline Transverse lie & $3.39 \%$ & $9.64 \%$ & - \\
\hline CPD & $40.75 \%$ & $9.96 \%$ & - \\
\hline PROM & $3.96 \%$ & $9.64 \%$ & - \\
\hline PIH & $1.5 \%$ & $5.78 \%$ & - \\
\hline Placenta previa & $0.94 \%$ & $3.21 \%$ & - \\
\hline Non progress of labour & 3.015 & $9.64 \%$ & $33.33 \%$ \\
\hline Unknown & $3.96 \%$ & $23.14 \%$ & - \\
\hline High risk pregnancy & $16.97 \%$ & - & - \\
\hline Threatened rupture & $1.88 \%$ & - & $14.58 \%$ \\
\hline Total 942 & 530 & 311 & 101 \\
\hline
\end{tabular}

As shown in Table 1, fetal distress was the major indications for emergency repeat CS $(52.08 \%)$, followed by non progress of labour $(33.33 \%)$. In elective repeat CS, major indication was CPD $(40.75 \%)$, followed by fetal distress $(16.41 \%)$.

Important per operative complication was adhesions and obliteration of UV fold.

Classical CS was done in 2 cases $(0.31 \%)$, Cesarean hysterectomy was done in 1 case $(0.15 \%)$. 
Table 2: Incidence of per operative complications in repeat cesarean section.

\begin{tabular}{|ll|}
\hline Complications & Percentage \\
\hline Adhesions & 12.25 \\
\hline Obliterated UV fold & 7.92 \\
\hline Thinned out lower segment & 3.32 \\
\hline Scar dehiscence & 1.06 \\
\hline Cesarean hysterectomy & 0.15 \\
\hline Broad ligament hematoma & 0.15 \\
\hline Others & 2.825 \\
\hline
\end{tabular}

Perinatal morbidity requiring admission to NICU for 21 babies $(3.32 \%)$ and mortality in 25 babies $(3.96 \%)$. Reasons for the mortality were, prematurity (11 babies) and congenital anomalies (3 babies), neonatal sepsis ( 9 babies) unknown reasons ( 2 babies).

\section{DISCUSSION}

There is a wide spread concern about the increasing proportion of births by cesarean section. Increasing rates of primary CS have led to an increased proportion of women with a history of prior cesarean delivery. Previous $\mathrm{CS}$ is the most common indication for repeat CS. Repeat CS predispose to an increased risk of intra operative complications like, scar dehiscence, adhesions, uterine rupture, significant hemorrhage, placenta previa, placenta acreta, bladder injury and hysterectomy. ${ }^{1}$

In the present study number of women who underwent elective repeat CS were 530 (56.26\%) and emergency repeat CS were 96 (10.19\%).

Table 3: Comparison of elective and emergency repeat $\mathrm{CS}$ with other studies.

\begin{tabular}{|c|c|c|}
\hline Author & $\begin{array}{l}\text { Elective } \\
\text { repeat CS \% }\end{array}$ & $\begin{array}{l}\text { Emergency } \\
\text { repeat CS \% }\end{array}$ \\
\hline Nazaneen $\mathrm{S}$ et al ${ }^{1}$ & 47.04 & 52.92 \\
\hline Vikas D et al $^{3}$ & 11.1 & 13.7 \\
\hline George $\mathrm{O}$ et $\mathrm{al}^{4}$ & 35.7 & 9.8 \\
\hline A Sharma et $\mathrm{al}^{5}$ & 30.39 & 42.15 \\
\hline Anagha $\mathrm{A}$ et $\mathrm{al}^{7}$ & 55.75 & 44.25 \\
\hline Akanksha $\mathrm{N}$ et $\mathrm{al}^{8}$ & 64.9 & 35.05 \\
\hline Present study & 56.26 & 10.19 \\
\hline
\end{tabular}

The most common intra operative complication observed was adhesions. Present study adhesions and obliteration of UV folds was seen in $19.17 \%$. Nazaneen $\mathrm{S}$ et al reported adhesions in $34.76 \%$, dense adhesions in $12 \%$, Anagha et al reported in $39.99 \%$, Singh S et al $26.92 \%$ ( 21 in 78 cases). ${ }^{1,7,8}$

Incidence of placenta previa was $0.94 \%$ and placenta acreta was not seen in our study. Nazaneen $\mathrm{S}$ et al reported placenta previa $4.3 \%$ and placenta acreta $2.46 \%$, Singh S et al reported $3 \%$ and $0.5 \%$ respectively. ${ }^{1,8}$
Incidence of cesarean hysterectomy in our study was $0.15 \%$, Singh $\mathrm{S}$ et al reported $1.5 \% .^{8}$ Nazaneen et al reported $1.53 \%$ as the study was done for previous 2,3 CS, they had 5 cases of placenta acreta required hysterectomy and incidence of thinned out scar was seen in $3.32 \%$ and scar dehiscence in $1.06 \%$. $^{1}$

Table 4: Comparison of per operative complications with other studies.

\begin{tabular}{|ll|lll|}
\hline Authors & $\begin{array}{l}\% \\
\text { Thinned } \\
\text { out scar }\end{array}$ & $\begin{array}{l}\% \text { Scar } \\
\text { dehiscence }\end{array}$ & $\begin{array}{l}\text { \% Scar } \\
\text { rupture }\end{array}$ & $\begin{array}{l}\% \\
\text { Rupture } \\
\text { uterus }\end{array}$ \\
\hline $\begin{array}{l}\text { Nazaneen } \\
\text { S et al }\end{array}$ & 18.46 & 7.69 & 0.3 & - \\
\hline $\begin{array}{l}\text { Nazlima } \\
\text { N et al }\end{array}$ & 23.13 & 3.33 & 0.3 & 1.1 \\
$\begin{array}{l}\text { Akanksha } \\
\text { N et al }\end{array}$ & - & 7.4 & - & - \\
\hline $\begin{array}{l}\text { Anagha } \\
\text { A et al }\end{array}$ & - & 2.75 & - & - \\
\hline $\begin{array}{l}\text { Singh S } \\
\text { et al }\end{array}$ & - & 7.69 & - & 1.0 \\
\hline $\begin{array}{l}\text { Present } \\
\text { study }\end{array}$ & 3.32 & 0.73 & - & 1.21 \\
\hline
\end{tabular}

In the present study there were $2(0.21 \%)$ cases with rupture uterus and subtotal hysterectomy was done. A Sharma et al5 reported $1.8 \%$ and Vikas D et al 3 reported $2 \%$ of rupture uterus in their study. Singh A et al reported incidence of rupture uterus $1.69 \%$ in previous $\mathrm{CS}$, and $0.15 \%$ in patients without previous $\mathrm{CS} .^{9}$

In the present study preterm CS was done for 11 cases. According to Nazaneen $\mathrm{S}$ et al preterm $\mathrm{C} \mathrm{S}$ was done in $18.15 \%$, due to patients admitted with emergency complaints like, pre term labour pains, PROM, and scar tenderness. ${ }^{1}$ Singh $\mathrm{S}$ et al reported $8 \%$ preterm $\mathrm{CS} .{ }^{8}$

In the present study perinatal morbidity was $3.32 \%$, mortality was $3.96 \%$. A Sharma et al reported $9.67 \%$ babies of elective CS and $2.32 \%$ in emergency CS babies were admitted to NICU. ${ }^{5}$ Vikas D et al reported outcome of babies in 30 emergency CS, done for failure of trial labour cases, stillbirths 2 babies, 2 neonatal death, sepsis in 4 babies, APGAR score less than 6 in 8 babies. $^{3}$ Akanksha $\mathrm{N}$ et al reported perinatal morbidity requiring NICU admissions for $6.4 \% .^{6}$ These studies suggest poor neonatal outcome for emergency CS babies.

\section{CONCLUSION}

The overall maternal risks are increased in repeat CS, but successful vaginal delivery is possible if women are managed well in tertiary care hospital. They should be counseled about maternal and perinatal risks and benefits of planned vaginal birth after cesarean section and elective repeat CS. Elective repeat CS should preferably be done at 39 completed weeks of gestation to avoid the risk of preterm birth. 
In conclusion it remains a challenge to strike a balance between concern for safety and the need to decrease CS rates. Due to limited facilities for fetal monitoring, most obstetrician tended to have a low threshold for elective repeat $\mathrm{CS}$, hence only about half of women with a previous CS were allowed attempt at VBAC.

Sonographic evaluation of lower uterine segment scar and myometrial thickness (both by TAS and TVS) is a safe reliable and non-invasive method for predicting the risk of scar dehiscence/rupture in women with previous cesarean section. Lower uterine scar thickness $>3.65 \mathrm{~mm}$ by trans abdominal scan is safe limit, above that VBAC can be offered.

Funding: No funding sources Conflict of interest: None declared

Ethical approval: The study was approved by the Institutional Ethics Committee

\section{REFERENCES}

1. Nazaneen S, Kumari A, Malhotra J, Rahman Z, Pankaj S, Alam A et al. Study of intraoperative complications associated with repeat cesarean sections at a tertiary care hospital in Eastern India. IOSR-JDMS. 2017;16(8):77-82.

2. Nargis N, Al Mahmood AK, Akhter D. Evaluation of uterine scar on repeat second cesarean section in patients with previous cesarean section. AKMMC J 2012;3(1):16-9.

3. Devkare V, Agarwal NV, Gayakwad N, Kamant S. Maternal and fetal outcome of VBAC after first previous LSCS in a tertiary care teaching hospital of Western India. Int J Curr Res Med Sci. 2017;3(7):817.
4. Ugwu GO, Iyoke CA, Onah HE, Egwuatu VE, Ezugwu FO. Maternal and perinatal outcomes of delivery after a previous cesarean section in Enugu, Southeast Nigeria: a prospective observational study. Int J Women's Health. 2014;6:301-5.

5. Sharma A, Sharma U, Chaudhary P, Acharya A, Chaudhary A, Hanspal J. Maternal and neonatal outcome in patients with history of previous one caesarean section. Indian Medical Gazette. 2012 May;145(5):169-73.

6. Nigam A, Anand R, Jain N. Study of obstetric and fetal outcome of post caesarean pregnancy. Int J Reprod Contracept Obstet Gynecol. 2017 Feb 3;4(1):215-8.

7. Jinturkar AA, Dongaonkar D. Study of obstetric and fetal outcome of post caesarean section pregnancy at tertiary care center. Int J Recent Trends Sci Tech. 2014;10(3):530-7.

8. Singh S, Dhama V, Chaudhary R, Karya U, Nanda $\mathrm{K}$. Maternal and fetal outcome in pregnant women with previous one lower segment cesarean section. Int J Reprod Contracept Obstet Gynecol. 2016 Dec 14;5(11):3815-9.

9. Singh A, Shrivastava C. Uterine rupture: still a harsh reality!. J Obstet Gynecol India. 2015 May;65(3):158-61.

10. Sharma C, Surya M, Soni A, Soni PK, Verma A, Verma S. Sonographic prediction of scar dehiscence in women with previous cesarean section. J Obstet Gynecol India. 2015 Apr;65(2):97-103.

Cite this article as: Chiniwar MA. Study of fetomaternal outcome in previous cesarean section. Int $\mathbf{J}$ Reprod Contracept Obstet Gynecol 2018;7:3848-51. 